This is the author's final, peer-reviewed manuscript as accepted for publication. The publisher-formatted version may be available through the publisher's web site or your institution's library.

\title{
Couples, money, and expectations: negotiating financial management roles to increase relationship satisfaction
}

Kristy L. Archuleta

\section{How to cite this manuscript}

If you make reference to this version of the manuscript, use the following information:

Archuleta, K. L. (2013). Couples, money, and expectations: Negotiating financial management roles to increase relationship satisfaction. Retrieved from http://krex.ksu.edu

\section{Published Version Information}

Citation: Archuleta, K. L. (2013). Couples, money, and expectations: Negotiating financial management roles to increase relationship satisfaction. Marriage \& Family Review, 49(5), 391-411.

Copyright: Copyright @ Taylor \& Francis Group, LLC

Digital Object Identifier (DOI): doi:10.1080/01494929.2013.766296

Publisher's Link: http://dx.doi.org/10.1080/01494929.2013.766296

This item was retrieved from the K-State Research Exchange (K-REx), the institutional repository of Kansas State University. K-REx is available at http://krex.ksu.edu 
Couples, Money, and Expectations: Negotiating Financial Management Roles to Increase

Relationship Satisfaction 


\begin{abstract}
How couples handle money has become a popular subject among scholars, practitioners, and the popular press. However, little is known about how finances should be treated within a clinical context. This study examined the financial management roles in which couples participate and their satisfaction level with these roles as well as couples' communication tactics surrounding money and their impact on relationship and financial satisfaction. Results suggested that having shared goals and values about money were a stronger predictor of relationship satisfaction than were communication strategies. In addition, satisfaction with one's financial management role participation may be more important than self-reported financial management roles each partner performs. In this study, financial management roles included 19 areas, including responsibilities such as bookkeeping, financial decision-making, and taxes.
\end{abstract}

Keywords: Financial management roles, financial satisfaction, relationship satisfaction, shared goals and values 


\section{Introduction and Literature Review}

The economic crisis that began in 2008 has prompted much discussion, especially in the media, about how couples should manage their financial obligations, manage conflicts about money, and make sound financial decisions (e.g., CNBC.com special reports on Love and Money, 2009; For Better or for Worse: Couples and Money Issues on forbes.com, 2011). Research has indicated that money is one of the top issues about which couples fight. Papp, Cummings, and Goeke-Morey (2009) examined the most discussed topics during marital conflict in the home. Papp and her colleagues concluded that money ranked sixth for husbands and fifth for wives among the most discussed topics during marital conflict. However, participants reported that conflict about money (i.e., spending, wages, salary, bills) was more intense and significant than non-money conflicts.

Several studies have found associations among household financial satisfaction, financial stressors, financial behaviors, debt, income, and marital quality (Archuleta, Britt, Tonn, \& Grable, 2011; Bradbury, Fincham, \& Beach, 2000; Britt, 2005; Britt, Grable, Nelson-Goff, \& White, 2008; Cano, Christain-Herman, O’Leary \& Avery-Leaf, 2002; Conger, Ge, Elder, Lorenz, \& Simons, 1994; Conger, Reuter, \& Elder, 1999; Dew, 2007; Dew, 2008; Dew \& Dakin, 2011; Geiss \& O’Leary, 1981; Grable, Britt, \& Cantrell, 2007; Kerkmann, Lee, Lown, and Allgood, 2000; Previti \& Amato, 2003). Among Marriage and Family Therapists, clients often report experiencing financial conflicts (Myhre \& Sporakowski, 1986); yet, relatively little empirical evidence has been added to the clinical knowledge of how to treat couples experiencing financial problems. Bagarozzi and Bagarozzi (1980) suggested that financial issues should be addressed first with families who present financial issues in a therapy setting. They reasoned that addressing the financial problems first would lower their stress so that families 
could more easily concentrate on repairing family dynamics. Aniol and Snyder (1997) found that approximately $1 / 3$ of couples seeking marital counseling presented with financial distress, while $1 / 3$ of couples seeking financial counseling reported having marital problems. This finding indicates that further understanding of how to treat couples experiencing financial problems is needed. The current study helps to further understand how relational therapists can assess household financial issues and help couples more effectively negotiate financial management roles and expectations.

Two research questions were developed for this study. These questions asked,

1. “Are increased effective couple relationship characteristics (i.e., positive communication and conflict strategies and higher perceived shared meaning in the relationship), increased involvement and satisfaction in his/her financial management roles, and increased financial satisfaction associated with increased one's satisfaction with his/her relationship?"

2. "Are increased effective couple relationship characteristics (i.e. positive communication and conflict strategies, and higher perceived shared meaning in the relationship), increased involvement and satisfaction with his/her financial management roles, and increased satisfaction with one's relationship associated with increased one's satisfaction with his/her financial situation?"

\section{Theoretical Framework}

A strong connection between couple relationships and household finances has been demonstrated in the literature (Britt, 2005; Johnson \& Booth, 1990; Kerkmann et al., 2000; Megunda \& Hira, 1990; Rosenblatt \& Keller, 1983). Based on empirical research, Archuleta (2008, 2009) developed a theoretical framework-Couples and Finances Theory (CFT) to help 
understand the dynamics related to couple relationships and their finances. In this study, CFT was used to guide the methodology of this study. Set within an ecological framework that assumes environmental factors (e.g. education, ethnicity, income, age, gender, economy, religion, culture, and community) affect the dynamics, CFT borrows many assumptions and concepts from systems theory and Deacon and Firebaugh's (1986) systemic family resource management model. Systems theory served as a foundation for the development of CFT.

The theory was initially created to help explain the associations between the couple relationship and the household financial process for married couples. In regards to same-sex couples, there is no empirical literature to suggest that CFT could not be applied to same-sex couples. In fact, Whitton and Buzzella's (2012) study of relationship education programs with same-sex couples suggested that the core relationship skills taught in most established relationship education programs for heterosexual couples can be useful in working with samesex couples. Whitton and Buzzella's results suggest that CFT could be applied to same-sex relationships.

A major assumption that CFT makes is that financial difficulties are linked to couple relationship problems. Pittman and Lloyd (1988) reported that financial stress is significantly related to lower marital quality. Several studies have shown that more responsible financial behaviors appear to be positively associated with relationship quality (Cano, Christian-Herman, O’Leary, \& Avery-Leaf, 2002; Geiss \& O’Leary, 1981). Rosenblatt and Keller (1983) described that couples, who reported greater economic distress, also reported greater blaming in their marriages. Johnson and Booth (1990) explained that those who underwent financial distress showed substantial increase in their likelihood of entertaining thoughts of divorce over a 5-year period. Almost half of this effect was due to increased depression. Taking these findings into 
account, CFT assumes that the linkage between the couple system and the financial process are circular in nature. This means that the household finances impact the couple relationship and the couple relationship impacts the household financial domain. In systems theory's terms, the two sub-systems of finances and the couple relationship are interrelated.

Another theoretical assumption in the development of CFT is that the couple relationship and the financial process operate within a larger context called an "ecosystem" (White \& Klein, 2002, p. 208). The elements of wholeness for CFT are both biophysical and environmental.

These elements include but are not limited to age, culture, religion, economy, culture, community, education, gender, and ethnicity. These elements and the couple relationship and financial process are interdependent with each other. Figure 1 displays the interconnectedness of the theory where $\mathrm{H} \& \mathrm{~W}$ represent husband and wife or individual characteristics; CRC represents couple relationship characteristics; and MQ corresponds to marital quality or, in the current study, relationship satisfaction. These three concepts can be described as the couple process. The financial process is defined by inputs, representing individual financial factors (e.g., financial knowledge, income, etc.); FMP corresponds with financial management practices; and FS signifies financial satisfaction. In the figure, each arrow represents empirical evidence linking one concept to another. For the purposes of this study, the CFT is being applied to a broader sample including cohabitating and married couples.

Insert Figure 1 here

\section{Method}

\section{Participants}

Participants were randomly selected from a financial service organization's non-public database in a Midwestern state, which contained 173,251 names and addresses. A total of 4,048 
surveys were mailed to 2,024 households. The relationship status as well as number of adults in the household was unknown to the researcher; therefore, two surveys were sent to each mailing address. Each survey packet contained two surveys. Recipients were given an incentive to complete the questionnaire by being entered into a drawing for one $\$ 100$ gift card and two $\$ 50$ gift cards upon completion and return of the questionnaires. Respondents could also indicate if they would like to receive the results of the survey. A follow-up postcard was sent three weeks following the initial mailing (Dillman, 2000). The follow-up postcards also included information about the deadline extension to return the survey, allowing more time for respondents to complete and mail the survey.

\section{Measurements}

The survey included assessments of demographic variables, financial management role involvement, satisfaction with financial management roles, financial satisfaction, and relationship quality. Demographic characteristics were used as control variables in this study. Gender was coded as male $=1$, otherwise 0. Relationship status was dummy coded so that respondents who reported being in a relationship $=1$, otherwise 0 . Education was dummy coded so that those holding a bachelor's degree or higher $=1$, otherwise 0 . Household gross income categories ranged from less than $\$ 20,000$ to $\$ 100,000$ or more. Household income was used as an ordinal measured variable. Years married and age were entered as interval variables.

Six standardized relationship quality measurements were used in this study, including the Kansas Marital Satisfaction Scale (KMSS) (Schumm, Paff-Bergen, Hatch, Obiorah, Copeland, Meens, \& Bugaighis, 1986) and five scales from the Sound Relationship House Scales (SRH) (Gottman, 2005). Financial management role involvement, financial management role satisfaction, and financial satisfaction were assessed using Likert-type scales. 
The Sound Relationship House Scales. The Sound Relationship House (SRH) Scales were based on the theory outlined in The Marriage Clinic (Gottman, 1999). The assessment goal of SRH Scales was to obtain a profile of the communication processes in a couple's relationship, which was a major interest in this study. Five scales were selected from Gottman's condensed SRH (Gottman, 2005) for use in the current study. These scales included: Harsh Start-up, Gridlock on Perpetual Issues, Compromise, Shared Meaning Roles, and Shared Meaning Goals. These scales were specifically chosen to identify perceptions of conflict patterns and shared views about roles, goals, and money within the relationship. The scales of Harsh Start-up, Gridlock on Perpetual Issues, and Compromise scales fit within the "Conflict" category of the SRH Scales. The scales of Shared Meaning Roles, Shared Meaning Goals, and Shared Meaning Symbols fit within the "Meaning" category of the SRH scales. Participants responded by indicating "True" or "False" to the condensed Harsh Start-up, Gridlock, Compromise, Shared Meaning Roles, and Shared Meaning Goals scales. In the original condensed SRH scales, each scale had a husband and a wife component. For the purposes of this study, the words "spouse," "husband" or "wife" were changed to the word, "partner" and did not distinguish between husband and wife in the phrasing of the statements. The response of "True" was given a numerical code of 1 and the response of "False" was numerically coded as 0 . Each scale was summed and could range from 0-5, with the exception of the Compromise scale, which could range from 0-4. Further detail about each of the five scales used in the study is provided below.

Conflict scales. The scales of Harsh Start-up, Gridlock on Perpetual Issues, and Compromise scales fit within the "Conflict" category of the SRH Scales. These scales assessed regulation of conflict. Harsh Start-up refers to whether the initial engagement of conflict is 
negative or not. Scores ranged from 0-5 $(\mathrm{M}=3.97$; $\mathrm{SD}=1.48)$ where 0 indicated more negative starts in conflict and 5 indicated more positive engagements with conflict.

One statement from the condensed scale was omitted and replaced by another question that came from the longer scale. The statement omitted was, "I find my partner's negativity unnerving and unsettling." This statement was replaced by, "I think my partner can be totally irrational." Based on the profile of potential respondents, the researcher concluded that the replacement statement was easier to comprehend. Internal consistency of the five scales was measured using Cronbach's alpha (Gottman, 2005). A shorter version of each scale and the internal consistency scores was used for the purposes of this study (Gottman, 2005). Internal consistency was measured using Cronbach's alpha scores (Cronbach, 1951) for both the current study and Gottman's (2005) condensed scales. Internal consistency for all conflict measures was very similar for this study as compared to previously reported scores (Gottman). In the current study, the Harsh Start-up Scale's internal consistency was .84. Omitting an original question from the condensed Harsh Start-up Scale and replacing it with another question from the longer version appears to have increased internal consistency of the scale.

Gridlock on Perpetual Issues refers to the emotional disengagement which partners employ while in conflict (e.g. does the partner feel respected during conflict, does the couple keep hurting each other, etc.). In the current study, scores ranged from 0-5 $(\mathrm{M}=3.98, \mathrm{SD}=1.35)$ where lower scores reflected increased likelihood to engage in gridlock. Internal consistency was .77. Compromise measures how well each spouse is at finding middle ground with his/her partner. The Compromise scale ranged from 0 to $4(\mathrm{M}=2.76$; $\mathrm{SD}=1.09)$ where higher scores indicated increased likelihood to engage in compromise. For survey brevity, one statement from the Compromise condensed scale was omitted. However, in this study, Cronbach's alpha was 
.39. Omitting a question from the condensed Compromise scale may have lowered the internal consistency.

Shared Goals and Values. The Shared Goals and Values Scale (Archuleta, Grable \& Britt, 2010) is a four-item measurement derived from Gottman's (2005) Shared Meaning Roles, Shared Meaning Goals, and Shared Meaning Symbols scales to assess couples' shared meaning about financial goals and values, life's goals, and autonomy. Items were measured using a 7point Likert-type scale, where $1=$ strongly disagree and $7=$ strongly agree. Response scores could range from 4-28, with lower scores indicating lower agreement on life goals and values and higher scores reflecting more agreement on these issues. The mean score was 23.28 ( $\mathrm{SD}=$ 4.94). Internal consistency was measured using Cronbach's alpha and indicated a high level of reliability $(\alpha=.88)$. The four statements included in this scale were:

(a) we have similar financial goals.

(b) our hopes and aspirations, as individuals and together for our children, for our life in general, and for our old age are quite compatible.

(c) we have similar values about the importance and meaning of money in our lives.

(d) we have similar values about "autonomy" and "independence."

Financial management roles. Financial management roles were assessed using two different 7-point Likert-type scales. The first component of the Financial Management Roles (FMR) assessment asked respondents to indicate the level of spousal involvement in specific financial management roles from a list of 19 topics (e.g. bookkeeping, financial decision-making, taxes, etc.). Financial management roles were identified in previous research of farm women (Archuleta, 2005). A score of " 1 " indicated that the financial management role was primarily the 
participant's responsibility. A score of "7" indicated that the role was the participant's partner's primary responsibility.

To help analyze the data, a score of 1 (participant's primary involvement) was recoded to 3; a score of 4 (joint involvement between two spouses) was recoded to 0 ; and a score of 7 , (partner's primary responsibility) was recoded to 3 . The purpose of recoding the scores was to allow the researcher to identify who was responsible for specific roles. Because not each participant was involved in every financial management role, an average FMR score was computed for each participant. These scores were then translated into absolute values with scores ranging from $0-3(\mathrm{M}=1.51 ; \mathrm{SD}=1.03)$ to indicate whether or not a participant was highly responsible or less responsible for the financial management roles in their household. A score of 0 indicated participant's primary responsibility, 1.5 reflected joint involvement, and 3 indicated partner's primary responsibility. Likewise, financial management role satisfaction items were summed and averaged for each participant.

The second component of the FMR assessment asked respondents his/her level of satisfaction of his/her involvement in each specific financial role (FMRS). A score of "1" indicated that the participant was "extremely unsatisfied" in his/her involvement. A score of "7" indicated that the participant was "extremely satisfied" in his/her involvement. The Mean for the FRMS was 5.00 and the standard deviation was 1.44 . No pre-exisiting reliability information was available for these scales; however, in this study, Cronbach's alphas were .93 for FMR and .78 for FRMS.

Financial satisfaction. Financial satisfaction (FS) was measured by asking respondents to determine how satisfied they were with their present financial situation, using a 10-point stair step question (Joo, 1998; Joo \& Grable, 2004; Porter \& Garman, 1993). A score of “1” indicated 
“extremely unsatisfied" and a score of 10 indicated "extremely satisfied" ( $M=6.10$; SD 2.44).

Given that the measure was a one-item scale, no reliability data were available for this measure; however, previous uses of the measure have shown strong validity in predicting subsequent behavior.

Relationship Satisfaction. The Kansas Marital Satisfaction Scale (KMSS) was used to measure relationship satisfaction (Schumm et al., 1986). In the present study, the questions from the KMSS were altered to reflect relationship satisfaction rather than marital satisfaction. The KMSS is a 3-item instrument; each item was measured using a 7-point Likert-type scale. The summated scale was scored with a possible range of 3 to $21(\mathrm{M}=18.34$; $\mathrm{SD}=3.86)$. Higher scores reflected greater relationship satisfaction. In the current study, the scale's Cronbach's alpha was .93, which matches well with previous reported reliability scores. Sabatelli (1988) reported that the KMSS appeared to establish test-retest reliability as well as criterion-related and construct validity. The KMSS was found to be significantly correlated with the Dyadic Adjustment Scale and the Quality of Marriage Index (Schumm et al., 1986).

\section{Analysis}

A Classification and Regression Tree (C\&RT) method was used to identify predicting factors of marital satisfaction and financial satisfaction. The purpose of classification analysis is to "understand what variables or interactions of variables drive the phenomenon" (Brieman, Friedman, Olshen, \& Stone, 1998, p. 6). C\&RT methods are nonparametric and sample size and multicollinearity are of less importance. A Gini splitting criterion was set and no penalty was given to the variables. In order to account for the relatively small sample size, the parent node was set at 10 respondents and the child nodes were set at 5 respondents. Lewis (2000) reported that decision trees are created by assigning respondents into categories. Categories continue to 
split until no other groups can be formed or until certain stopping limits are reached. In this study, possible trees were limited to five splits; however, the method did not reach the limit during any trial. All of the measured variables including demographic variables (i.e., age, gender, household gross income, education level) and measurements described above were entered two separate times into AnswerTree for SPSS to predict the target (dependent) variables of financial satisfaction and relationship satisfaction.

Multiple regression method was used to evaluate the strength of the predicting variables on relationship satisfaction and financial satisfaction. Regression analyses were used to determine the contribution to change in the dependent variable brought about by each independent variable (Nardi, 2006). Field (2005) explained regression can tell about the power of predicting variables. Because the sample was not large enough to measure the predicting strength of all of the independent variables, the C\&RT methods was use to determine which independent variables indeed contributed most to the dependent variables. Once this process was completed, regression analyses were performed using the independent variables suggested by the C\&RT analysis to further analyze the outcome of the decision tree method.

\section{Results}

The survey included assessment of demographic variables, financial management role involvement, satisfaction with financial management roles, financial satisfaction, and relationship quality. Financial satisfaction and relationship satisfaction served as the dependent variables in the study; while demographic variables, financial management role involvement, financial management role satisfaction, conflict scales and meaning scales served as the independent variables.

\section{Sample Characteristics}


Of the 4,048 surveys that were mailed to 2,024 households, a total of 177 surveys were returned; 27 survey packets were returned undeliverable, and 23 surveys were returned unusable with missing data. For the purposes of this study, ninety-four respondents reported that they were in an intimate relationship at the time of the survey and completed relevant survey items $(\mathrm{N}=94)$. The response rate was uncertain and difficult to determine because it is unknown if the second survey included in the survey packet was relevant to the household; however, the response rate was no higher than $7.5 \%$. Table 1 summarizes the sample characteristics and the coding for each of the demographic variables.

Insert Table 1 Here

\section{Research Question 1 - Relationship Satisfaction}

Classification and Regression Tree (C\&RT) and multiple regression methodologies were used to address the two research questions stated at the outset of the paper. C\&RT was used to reduce the number of variables to an acceptable number for use in regression models. The first research question asked if one partner engaged in increased effective couple relationship characteristics (i.e. effective communication and conflict strategies and higher perceived shared meaning in the relationship), was more involved and satisfied with his/her financial management roles, and more financially satisfied, would he/she be more satisfied in his/her relationship?

To examine question one, demographic variables (i.e. age, gender, household gross income, years married, religiosity, and education), as well as the condensed Sound Relationship House scales, Financial Management Role Involvement scale, Financial Management Role Satisfaction scale, and financial satisfaction scale were entered as possible independent variables associated with the dependent variable, relationship satisfaction (i.e., Kansas Marital Satisfaction scale). The decision tree (Figure 2) illustrates that shared roles is one of the most important 
factors influencing marital satisfaction. Shared roles produced a level of prediction improvement of $5.77(\mathrm{M}=19.07)$. If a respondent scored a 2.5 or more (Node 2) on shared roles (maximum value $=5$ ), then they were predicted to be more satisfied with their marriage than those who had a lower score (Node 1). For those scoring 2.5 or higher, Gridlock became the next important factor producing a prediction improvement rate of $1.79(\mathrm{M}=19.63)$. Those who engaged in gridlock less (Node 6) were more satisfied than those who did not (Node 5). For those scoring higher than a 2.5 on the Gridlock scale ( $\max$ value $=5$ ), Harsh Start-Up (Node 10) followed by Shared Goals and Values (Node 12), then gender (Node 14) became predicting factors. Financial role satisfaction (Node 8 ) became a predicting factor for those who scored less than 2.5 on Gridlock. Average role satisfaction produced an improvement rate of $.50(\mathrm{M}=18.0)$.

Insert Figure 2 Here

Multiple regression was used to confirm the model. The variables identified as predictors of relationship satisfaction were entered as independent variables into the regression analysis. This model was statistically significant, accounting for $57 \%$ of the variance in relationship satisfaction $(\mathrm{F}=16.39, \mathrm{p}<.01)$. Two of the independent variables, Shared Roles and Shared Goals \& Values, were found to be statistically significant at the $\rho<.01$ level. Table 2 displays these results. Couple relationship characteristics (shared roles, gridlock, harsh start-up, shared goals and values) along with financial role satisfaction were found to be significant predictors of relationship satisfaction. The model was also confirmed when accounting for gender.

Insert Table 2 Here

\section{Research Question 2 - Financial Satisfaction}

The second research question asked whether increased effective couple relationship characteristics (i.e. positive communication and conflict strategies, and higher perceived shared 
meaning in the relationship), increased involvement and satisfaction with his/her financial management roles, and increased relationship satisfaction in his/her relationship, would have an impact on one's financial satisfaction. To examine this question, all of the variables used in the first test were entered into the CR\&T analysis, with two differences. First, financial satisfaction was entered as the dependent variable and relationship satisfaction was entered as an independent variable. The decision tree (Figure 3) shows that household gross annual income was the most influential predictor of financial satisfaction with a prediction improvement of .98 $(\mathrm{M}=6.40)$. If a respondent scored more than $1.5(\max =10)$ on household gross income (Node 2), then it was predicted that they were more financially satisfied than those who scored less than 1.5 (Node 1). Shared Goals and Values was the second most important predictor with a prediction improvement rate of $.56(\mathrm{M}=6.81)$. Other predicting factors were age with an improvement rate of .29 $(\mathrm{M}=7.18)$, financial role satisfaction with a prediction improvement rate of $.24(\mathrm{M}=7.64)$, and years married with a prediction improvement rate of $.11(\mathrm{M}=7.86)$.

The five variables identified in the decision tree were entered as independent variables in a multiple regression analysis of financial satisfaction. With all five factors (i.e. Shared Goals \& Values, FRMS, age, household income, and years married) entered simultaneously, this model accounted for $29 \%$ of the explained variance in financial satisfaction. The model was statistically significant $(\mathrm{F}=5.64, \rho<.01)$, with two of the individual variables, Shared Goals and Values and household income, being significant at the $\rho<.05$ level. Table 3 displays the results for the multiple regression analysis.

Insert Table 3 Here

\section{Discussion}


Several findings from this study are important. First, evidence from C\&RT analyses, as well as multiple regression analyses, found that having shared views about roles within the relationship as well as having perceived shared goals and values about money and autonomy were more likely to be predicting factors for marital satisfaction than how a couple communicated during conflict. In regards to a couple's perceived financial satisfaction, having increased household income and perceived shared goals and values about money and autonomy as well as having higher financial management role satisfaction and increased age were among the important predicting factors.

CFT can help make sense of these findings. The interconnectedness of the couple process and the financial process, represented in Figure 1, helps to explain how couple relationship characteristics are vital not only to the couple relationship but also to the financial process. The findings in this study indicate that it is important for couples to share similar views and goals about their money, life's goals, and autonomy and independence both for their relationship satisfaction and for their financial satisfaction. Gottman (1999) explained that honoring each other's life dreams is important in creating positive affective interaction within a couple. This does not mean that a couple has to agree on all of each other's dreams. Instead, they can provide support for their partner's life dreams or share in them fully. In other words, respect of the other's views and goals about money is important for a couple's relationship with each other and for their own financial satisfaction. This finding is similar to Schramm, Marshall, Harris, and Lee's (2005) results where they found that respect was a key predictor of marital satisfaction.

In regards to financial roles, satisfaction of one's financial roles may be more of a predictor of financial satisfaction than the actual role in which partners carry out. Although financial role satisfaction was not significant in the regression analysis, it was shown to be a 
predictor in both CR\&T models. Hiller and Philliber (1986) studied couple expectations and found that couples agreed that money management should be a shared responsibility. This may imply that couples "specialize" or choose to participate in specific financial roles because they enjoy doing them. Skogrand, Johnson, Horrocks, and Defrain (2011) supported this notion when they discovered that the most important aspect of who made financial decisions in happily married couples' relationships was based on who had experience, who had time, and who enjoyed doing it.

The demographic variables of household income, age, and years married were shown to be predicting factors of financial satisfaction according to CR\&T; household income proved to be especially important in the multiple regression analysis. Couples appear to place emphasis on having a certain level household income to increase financial satisfaction. This may be similar to Davis and Schumm (1987) who found that annual family income was an important factor for understanding savings satisfaction among higher income earning families. Families who earned at least $\$ 9,000$ were more likely to save, increasing their satisfaction. In addition, Britt’s (2005) findings may be able to help explain this finding; she found that couples need to have a certain level of household income to meet their financial obligations. Meeting the financial obligations appeared to lead to increased financial satisfaction. Once these obligations were met, household income did not seem to be factor for predicting financial satisfaction.

Age and years married have been found to be predictors of relationship satisfaction where satisfaction in the relationship increases with age and the number of years married (Glenn, 1990; Orbuch, House, Mero, \& Webster, 1996). These researchers suggested that relationship satisfaction increases after children leave the home. The same could be true in regards to financial satisfaction. A couple may have more disposable income after children leave the home 
and the parents are no longer financially responsible for them. Couples are then more likely to be able to achieve financial goals that they were unable to attain when they were financially responsible for the children.

\section{Implications}

Finances are a neglected area in relationship therapy training (Poduska \& Allred, 1990) and mental health training in general. As a result, most therapists have very little experience addressing money within the context of couples' therapy. Myhre and Sporakowski (1986) reported that most Marriage and Family therapists believed that prospective clinicians needed training in financial counseling. The results from this study affirm that therapists should consider finances as a major component in a couple's relationship. Two major implications exist as a result of this study for relationship therapists. First, the Shared Goals \& Values scale can prove to be a valuable tool in assessing couples' perceived shared views about money. The scale can help clinicians facilitate a dialogue between partners about financial expectations within the relationship. If couples differ in their financial goals and values, then the therapist may want to focus on issues of enhancing respect for and understanding of each other's views.

Second, the findings indicate that couples tend to specialize in financial roles. If couples specialize in financial roles, it may be important for clinicians to assess financial role involvement and their satisfaction level with their current financial role division. If one or both partners are participating in tasks that they do not like or that they feel incompetent in doing, then this may have an impact on both their financial and relationship satisfaction.

\section{Limitations}

Several limitations exist concerning generalizability and sample size. First, the sample was ethnically homogeneous even though random sampling methods were used. The majority of 
respondents (89.5\%) defined themselves as European American. Native American was the second most reported ethnicity (8.9\%). Seven respondents described themselves as "other," but there were no other ethnicities reported.

Second, the inability to guarantee that respondents completed their surveys without consulting one another is a weakness. For example, a couple received the survey packet and the wife completed both of the surveys, rather than completing one survey and the husband's completing the other survey. As a result, the surveys could have been completed from the wife's perception for filling out the wife's survey and the wife's perception of how she believed her husband would have answered the questions in the spouse's survey. In addition, the sample was comprised of some couples, where both partners completed the survey. In this study, the sample was treated as individual data rather than couple data; however, having both couple data and individual data may also have negatively impacted generalizability.

Third, slightly over half of the respondents indicated living on a farm or in a rural area $(n=55)$. Near the same time that the survey for the current study was mailed, the U. S. Department of Agriculture's Census of Agriculture survey was due; completion of the Census of Agriculture was required by the U.S. government for those with farming interests. The lengthy nature of both surveys may have also deterred individuals from completing the current study's survey.

Fourth, Americans receive mass amounts of mailings, advertising, and solicitations for consumers to buy products. It is likely that one can assume that some recipients of the survey packet believed the packet was junk mail although the return address was from a university. Fifth, the majority of recipients were located in a different state than the university, which may have also deterred recipients from responding. A sixth possibility is that Americans have 
increased awareness of identity theft. Numerous newscasts have reported on the dangers of revealing personal information to unknown sources. Although no identifying information was requested in the current study's survey, it is possible that individuals were less likely to discuss personal matters when they do not have a personal connection to the source.

Fifth, Dillman (2009) recommended mailing a letter prior to sending a survey to tell potential participants that they will be receiving a survey and then mailing at least three followup reminders about the survey. No letter was mailed in advance and the use of only one followup contact here no doubt limited the final response rate. The use of a condition incentive may have led potential respondents to question their actual chances of winning the incentive in comparison to Dillman's (2009) recommendation of including actual cash as both a definitive, concrete incentive and as a symbol of trust. Due to the limited funding for this study, multiple mailings and a cash incentive for each participant were not feasible.

Finally, it has been the researcher's clinical experience that couples are more willing to talk about their sexual relationship than their financial relationship. The researcher has observed that issues of money are deeply rooted emotionally and individuals have difficulty expressing their personal beliefs and feelings about the meaning of money and why they manage the money the way they do.

\section{Conclusions}

This study has shown that there are several significant predicting factors associated with financial satisfaction and relationship satisfaction. Increased shared roles, shared goals and values and financial role satisfaction, and decreased harsh start-up and gridlock were important predicting factors for relationship satisfaction. Increased household income, increased shared goals and values, increased financial role satisfaction, and increased age and years married were 
important predicting factors of financial satisfaction. Couple and relationship therapists should assess couples' shared goals and values about money and life goals. Therapists can also apply the knowledge gained from this study to facilitate conversations about couples' expectations in regards to financial management roles and the couple relationship characteristics needed to be satisfied in both their relationship and in their financial situation. 


\section{References}

Archuleta, K. L., Britt, S. L., Tonn, T., \& Grable, J.E. (2011). Financial satisfaction and financial stressors in marital satisfaction. Psychological Reports, 108(2), 563-576.

Archuleta, K. L. (2009). Couples, money, and expectations: Negotiating financial management roles to increase relationship satisfaction. Paper presented as part of the Symposium on Predicting Relationship Outcomes from Shared and Realistic Couple Expectations at the annual 2009 National Council on Family Relations conference, San Francisco, CA.

Archuleta, K.L., Grable, J. E., \& Britt, S. L. (2010). Shared goals and values: Towards an understanding of financial and marital satisfaction. Proceedings of the Eastern Family Economics and Resource Management Association.

Aniol, J. C., \& Snyder, D. K. (1997). Differential assessment of financial and relationship distress: Implications for couples therapy. Journal of Marriage and Family Therapy, 23 (3), 347-352

Archuleta, K. L. (2005). Farm wives level of involvement in the financial management of the farm operation and their perception of marital quality. Unpublished master's thesis, Kansas State University, Manhattan, KS.

Archuleta, K. L. (2008). The impact of dyadic processes and financial management roles on farm couples. Unpublished doctoral dissertation, Kansas State University, Manhattan, KS.

Archuleta, K. L. (November 2009). Dyadic processes influencing household financial management. In K. Campbell (Chair), Predicting Relationship Outcomes from Shared and Realistic Couple Expectations. Symposium presented at the National Council of Family Relations, San Francisco, CA. 
Bagarozzi, J. I., \& Bagarozzi, D. A. (1980). Financial counseling: A self control model for the family. Family Relations, 29, 396-403.

Bradbury, T. N., Fincham, F.D., \& Beach, S. R. H. (2000). Research on thenautre and determinants of marital satisfaction: A decade in review. Journal of Marriage and the Family, 62 (4), 964-980.

Breiman, L., Fiedman, J. H., Olshen, R. A., \& Stone, C. J. (1998). Classification and regression trees. Boca Raton, FL: Chapman \& Hall/CRC.

Britt, S. L. (2005). Using financial behaviors to project relationship satisfaction. Proceedings of the Association for Financial Counseling and Planning Education, 53-60.

Britt, S. L., Grable, J.E., Nelson-Goff, B., White, M. B. (2008). The influence of perceived spending behaviors on relationship satisfaction. Financial Counseling and Planning, 19(1), 31-43.

Cano, A. Christain-Herman, J., O’Leary, K.D., \& Avery-Leaf, S. (2002). Antecedents and consequences of negative marital stressors. Journal of Marriage and Family Therapy, 28, $145-151$.

CNBC.com (2009). Love and Money Special Report. Retrieved May 1, 2009 from http://www.cnbc.com/id/28750702/

Conger, R. D., Gee, X., \& Lorenz, F. O. (1994). Economic stress and marital relations. In R.D. Conger \& G. H. Elder (Eds.), Families in troubled times (pp. 187-203). New York: Aldine De Gruyter.

Conger, R. D., Rueter, M. A., Elder, G. H., Jr., (1999). Couple resilience to economic pressure. Journal of Personality and Social Psychology, 76, 54-71. 
Corcoran, K. \& Fischer, J. (2000). Measures for clinical practice ( ${ }^{\text {rd }}$ ed., Vol. 1). New York: The Free Press.

Cronbach, L. J. (1951). Coefficient alpha and the internal structure of tests. Pscychometrika, 16(3), 297-334.

Davis, E. P., \& Schumm, W. R. (1987). Savings behavior and satisfaction with savings: A comparison of low- and high-Income groups. Home Economics Research Journal, 15(4), 247-256.

Dew, J. (2007). Two sides of the same coin? The differing roles of assets and consumer debt in marriage. Journal of Family and Economic Issues, 28 (1), 89-104.

Dew, J. (2008). Debt change and marital satisfaction change in recently married couples. Family Relations, 57 (1), 60-71.

Dew, J., \& Dakin, J. (2011). Financial disagreements and marital conflict tactics. Journal of Financial Therapy, 2(1), 23-42.

Dillman, D. A. (2009). Mail and internet surveys: The tailored design method ( ${ }^{\text {rd }}$ ed). New York: John Wiley \& Sons, Inc.

Field, A. (2005). Discovering statistics using SPSS. Thousand Oaks, CA: Sage Publications.

Geiss, S. K., \& O’Leary, K. D. (1981). Therapist ratings of frequency and severity of marital problems: Implications for research. Journal of Marital and Family Therapy, 7, 515-520.

Glenn, N. D. (1990). Quantitative research on marital quality in the 1980s: A critical review. Journal of Marriage and the Family, 52, 818-831.

Gottman, J. M. (1999). The marriage clinic. New York: W. W. Norton \& Company.

Gottman, J. M. (2005). The reduced sound relationship house scales. Unpublished manuscript, One Stone, Inc. 
Gottman, J. M., Coan, J., Carrere, S., \& Swanson, C. (1998). Predicting marital happiness and stability from newlywed interactions. Journal of Marriage and the Family, 60, 5-22.

Grable, J. E. (2000). Financial risk tolerance and additional factors that affect risk taking in everyday money matters. Journal of Business and Psychology, 14, 625-630.

Grable, J. E., Britt, S. L., \& Cantrell, J. (2007). An exploratory study of the role financial satisfaction has on the thought of subsequent divorce. Family and Consumer Sciences Research Journal, 36(2), 130-150.

Hendrick, S. S. (1988). A generic measure of relationship satisfaction. Journal of Marriage and the Family, 50, 93-98.

Hiller, D. V., \& Philliber, W. W. (1986). The division of labor in contemporary marriage: expectations, perceptions, and performance, Social Problems, 33, 191-201.

Johnson, D. R., \& Booth, A. (1998). Marital quality: A product of the dyadic environment or individual factors? Social Forces, 76, 883-904.

Johnson, D. R., \& Booth, A. (1990). Rural economic decline and marital quality: A panel study of farm marriages. Family Relations, 39, 159-165.

Joo, S. (1998). Personal financial wellness and worker job productivity. Unpublished doctoral dissertation, Virginia Polytechnic Institute and State University, Blacksburg.

Joo, S. \& Grable, J. E. (2004). An explanatory framework of the determinants of financial satisfaction. Journal of Family and Economic Issues, 25, 25-50.

Kerkmann, B. C., Lee, T. R., Lown, J. M., \& Allgood, S. M. (2000). Financial management, financial problems and marital satisfaction among recently married university students. Financial Counseling and Planning, 11, 55-64. 
Lewis, R. J. (2000). An Introduction to classification and regression tree (CART) analysis. Paper presented at the Annual of the Society for Academic Emergency Medicine. Paper retrieved from http://citeseerx.ist.psu.edu/viewdoc/download?doi=10.1.1.95.4103\&rep=rep1\&type=pdf.

Megunda, O. M., \& Hira, T. K. (1990). Assessing the causal relationship among communication, money management practices, satisfaction with financial status, and satisfaction with quality of life. Lifestyles: family and Economic Issues, 11, 343-360.

Myhre, D. C., \& Sporakowski, M. J. (1986). Financial problems and the significance of financial counseling to the practice and profession of marital and family therapy. Marriage \& Family Review, 10(1), 157-169.

Nardi, P. M. (2006). Interpreting data: A guide to understanding research. Boston: Pearson Education, Inc.

Nelson, T. S., \& Allred, D.D. (2005). Survey research in marriage and family therapy. In D. H. Sprenkle \& F. P. Piercy (Eds.), Research methods in family therapy, $\left(2^{\text {nd }}\right.$ ed., pp. 211237). New York: Guilford Press.

Nichols, M. P. \& Schwartz, R. C. (2001). Family Therapy: Concepts and methods. Boston: Allyn \& Bacon.

Orbuch, T. L., House, J. S., Mero, R. P., Webster, P. S. (1996). Marital quality over the life course. Social Psychology Quarterly, 59, 162-171.

Pahl, J. (2000). Couples and their money: Patterns of accounting and accountability in the domestic economy. Accounting, Auditing, \& Accountability Journal, 13, 502-517

Papp, L. M., Cummings, E. M., \& Goeke-Morey, M. C. (2009). For richer, for poorer: Money as a topic of marital conflict in the home. Family Relations, 58, 91-103. 
Pittman, J. F., \& Lloyd, S. A. (1988). Quality of family life, social support, and stress. Journal of Marriage and the Family, 50, 53-67.

Poduska, B. E. \& Allred, G. H. (1990). Family finances: The missing link in MFT training. The American Journal of Family Therapy, 18 (2), 161-168.

Previti, D., \& Amato, P. R. (2003). Why stay married? Rewards, barriers, and marital stability. Journal of Marriage and Family, 65, 561-573

Rosenblatt, P. C., \& Keller, L., O., (1983). Economic vulnerability and economic stress in farm couples. Family Relations, 32, 567-573.

Sabatelli, R. M. (1988). Measurement issues in marital research: A review and critique of contemporary survey instruments. Journal of Marriage \& the Family, 50, 891-915.

Schramm, D. G., Marshall, J. P., Harris, V. W. Harris, \& Lee, T. R (2005) After "I Do": The newlywed transition. Marriage \& Family Review, 38(1), 4567.doi:10.1300/J002v38n01_05

Schumm, W. R., Paff-Bergen, L. A., Hatch, R. C., Obiorah, F. C., Copeland, J. M., Meens, L. D., and Bugaighis, M. A. (1986). Concurrent and discriminant validity of the Kansas Marital Satisfaction Scale. Journal of Marriage and the Family, 48, 381-387.

Snyder, D.K., \& Mangrum, L. F. (2005) Approaches to prediction: Correlation, regression and classification techniques. In D. H. Sprenkle \& F. P. Piercy (Eds.) Research methods in family therapy (pp. 368-402). New York: Guilford Press.

Skogrand, L., Johnson, A. C., Horrocks, A. M., \& Defrain, J. (2011). Financial management practices of couples with great marriages. Journal of Family and Economic Issues, 32, 27-35. doi: 10.1007/s10834-010-9195-2

White, J. M., \& Klein, D.M. (2002). Family theories (2nd Ed). Thousand Oaks: Sage 
Publications.

Whitton, S. W., \& Buzzella, B. A., (2012). Using relationship education programs with same-sex couples: A preliminary evaluation of program utility and needed modifications. Marriage \& Family Review, 48, 669-690. 
Table 1 Sample Characteristics

\begin{tabular}{|c|c|c|c|}
\hline Sample Characteristic and Code & $\mathrm{N}$ & Mean & SD \\
\hline Age & 126 & 53.30 & 16.21 \\
\hline $\begin{array}{l}\text { Relationship Status } \\
\text { Single, Separated, Divorced, Widowed }=0\end{array}$ & 126 & .74 & .44 \\
\hline \multicolumn{4}{|l|}{$\begin{array}{l}\text { Married, Remarried, Not Married but living } \\
\text { with significant other }=1\end{array}$} \\
\hline Years Married & 87 & 28.34 & 16.649 \\
\hline $\begin{array}{l}\text { Gender } \\
\text { Female }=0 \\
\text { Male }=1\end{array}$ & 126 & .50 & .50 \\
\hline $\begin{array}{l}\text { Level of Highest Education } \\
\text { Some High School, High School Diploma, } \\
\text { Some College, and Associates Degree=0 }\end{array}$ & 124 & .42 & .50 \\
\hline \multicolumn{4}{|l|}{$\begin{array}{l}\text { Bachelor's Degree, Some Graduate School, } \\
\text { Master's Degree, Ph.D. Degree=1 }\end{array}$} \\
\hline $\begin{array}{l}\text { Primary Ancestry } \\
\text { European-American }=1 \\
\text { American Indian or Alaska Native }=2 \\
\text { Asian }=3 \\
\text { Pacific Islander }=4 \\
\text { Hispanic/Latino }=5 \\
\text { African-American }=6 \\
\text { Other }=7\end{array}$ & $\begin{array}{r}124 \\
111 \\
11 \\
0 \\
0 \\
1 \\
0 \\
1\end{array}$ & $\begin{array}{r}1.17 \\
89.5 \% \\
8.9 \% \\
0 \\
0 \\
0 \\
0 \\
1.9 \%\end{array}$ & .695 \\
\hline $\begin{array}{l}\text { Household Income } \\
\text { Less than } \$ 20,000=1 \\
\$ 20,000-\$ 30,000=2 \\
\$ 30,000-\$ 40,000=3 \\
\$ 40,000-\$ 50,000=4 \\
\$ 50,000-\$ 60,000=5 \\
\$ 60,000-\$ 70,000=6 \\
\$ 70,000-\$ 80,000=7 \\
\$ 80,000-\$ 90,000=8 \\
\$ 90,000-\$ 100,000=9 \\
\text { More than } \$ 100,000=10\end{array}$ & 116 & 5.10 & 3.22 \\
\hline Religiosity & 125 & 1.85 & .992 \\
\hline
\end{tabular}


Table 2

Summary of Regression Analysis for Individual Variables Predicting Relationship Satisfaction

\begin{tabular}{lllll}
\hline Variable & B & SE B & $\beta$ & $\rho$ \\
\hline Shared Goals \& Values Scale & .23 & .09 & .30 & $.00^{* *}$ \\
Shared Roles & 1.21 & .34 & .36 & $.00^{* *}$ \\
Gridlock & -.03 & .39 & -.01 & .94 \\
Harsh Start-up & .62 & .33 & .24 & .07 \\
Gender & .05 & .61 & .01 & .93 \\
\hline
\end{tabular}

$* * \rho<.01$ 
Table 3

Summary of Regression Analysis for Individual Variables Predicting Financial Satisfaction

\begin{tabular}{lllll}
\hline Variable & B & SE B & $\beta$ & $\rho$ \\
\hline Shared Goals \& Values & .10 & 1.55 & .27 & $.01^{*}$ \\
Financial Management & .34 & .20 & .19 & .09 \\
$\begin{array}{l}\text { Role Satisfaction } \\
\text { Annual Household }\end{array}$ & .15 & .07 & .23 & $.03^{*}$ \\
$\begin{array}{l}\text { Gross Income } \\
\text { Age }\end{array}$ & .03 & .02 & .18 & .18 \\
Years Married & .02 & .02 & .16 & .24 \\
\hline
\end{tabular}

$* \rho<.05$

$* * \rho<.01$ 
Figure 1. Couples and Money Theoretical Framework

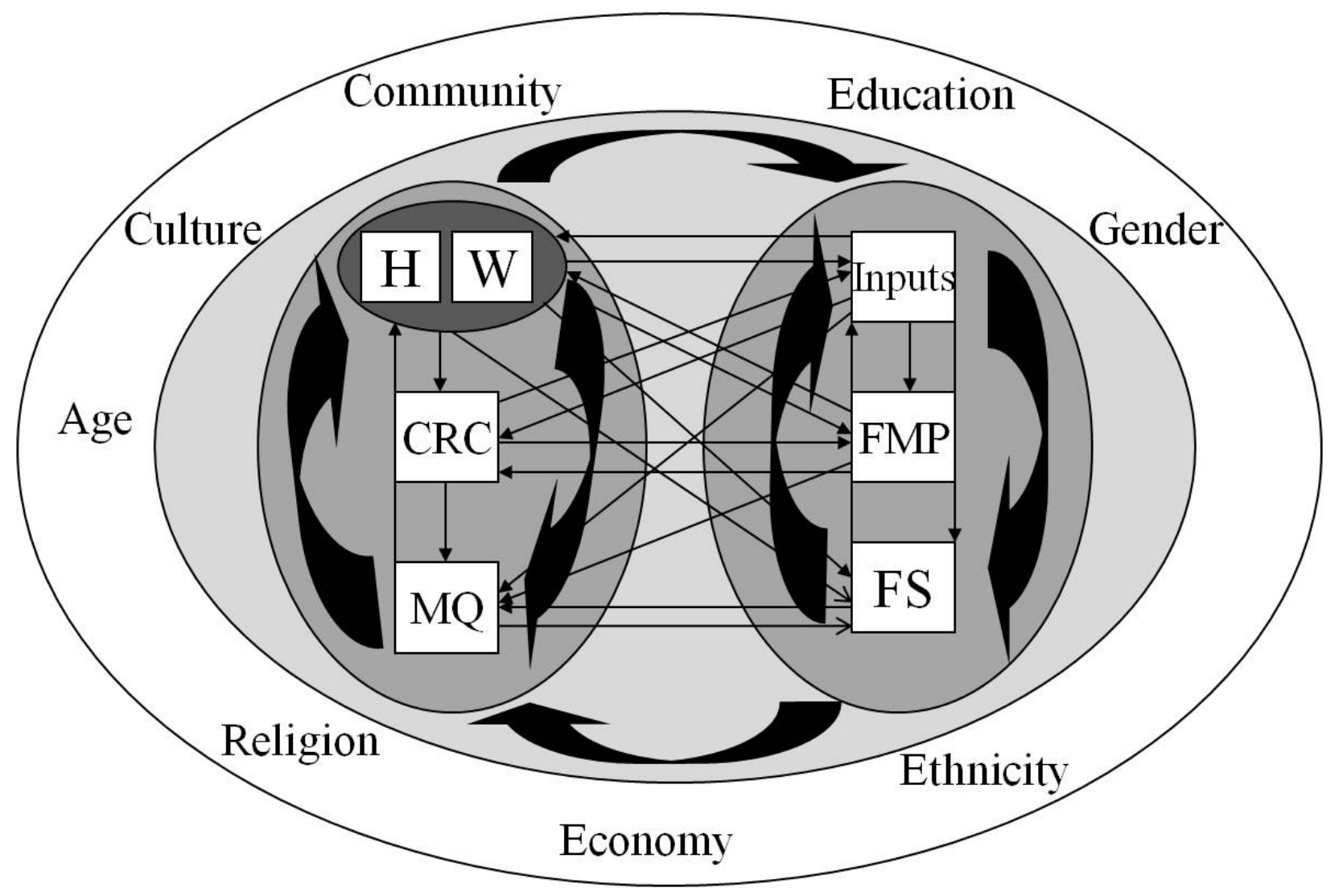


Figure 2. Relationship Satisfaction CR\&T Model

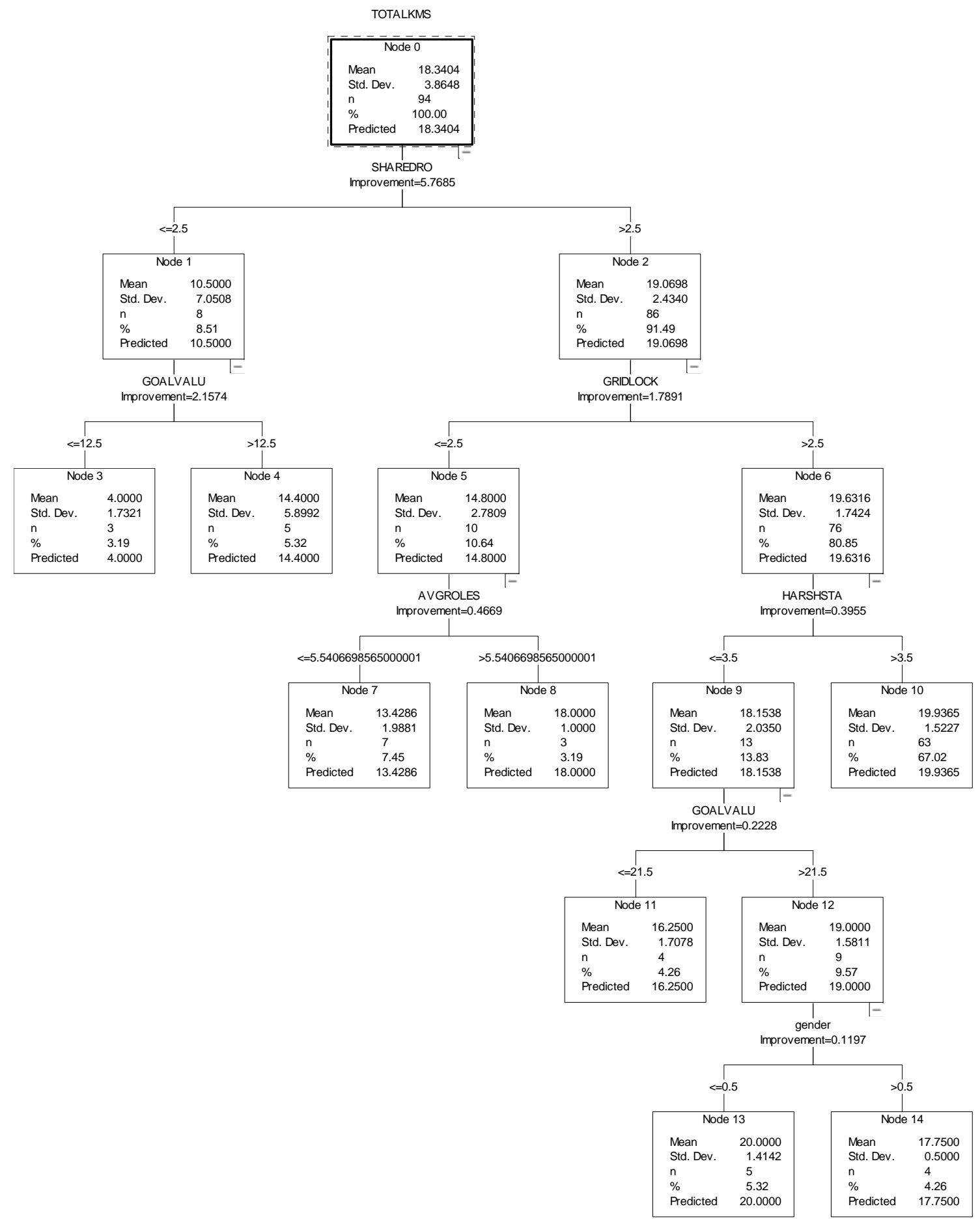


Figure 3. Financial Satisfaction Decision Tree Model

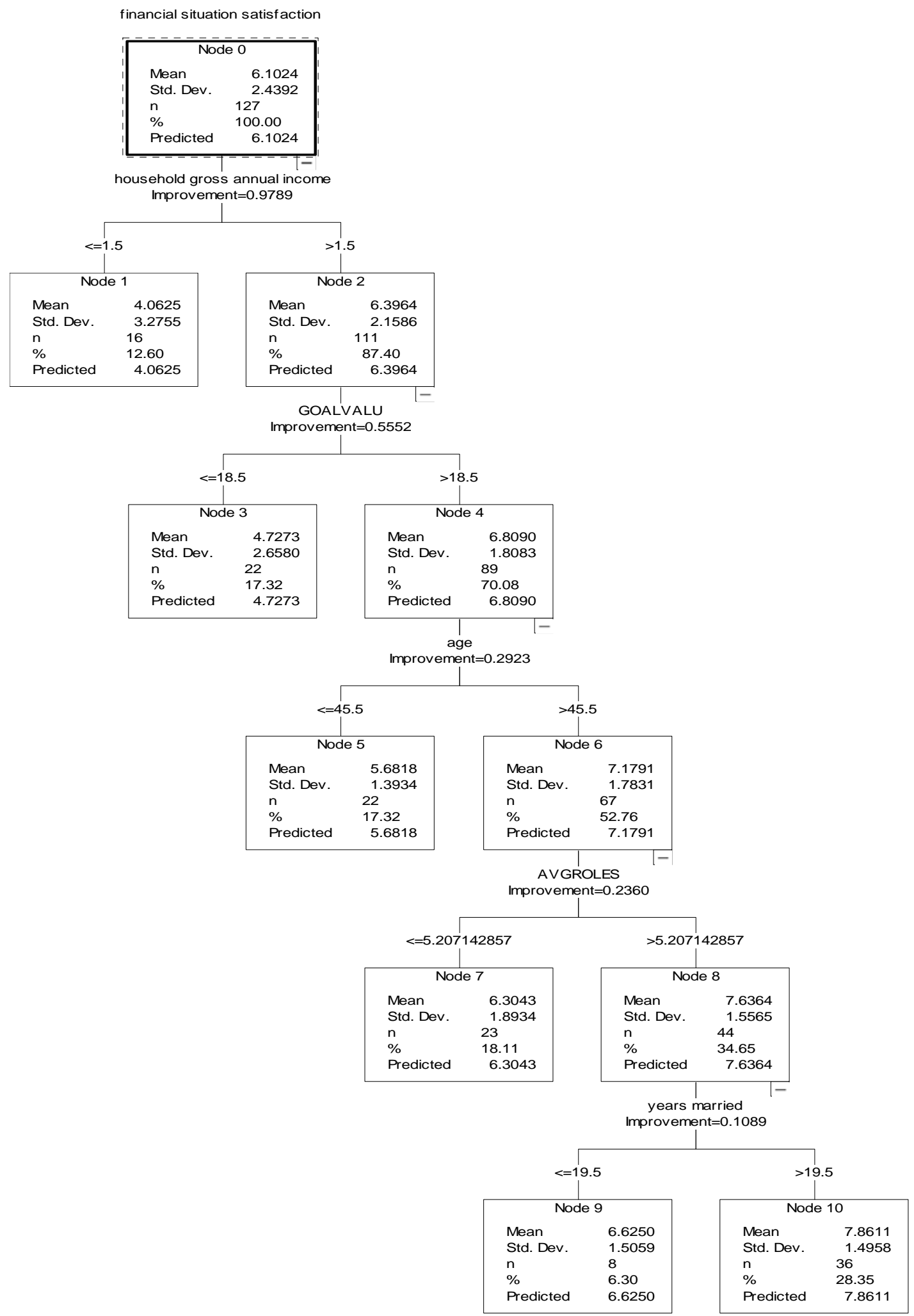

